hydrocortisone 17-butyrate was not included in this part of Dr Munro's and Miss Wilson's experiments. Academisch Ziekenhuis,
Leiden, Holland

M K POLANO 1 Hendrikse, J C M, and Moolenaar, A J, Derma-
tologica, $1973,147,191$.

\section{Aeromedical evacuation of the seriously ill}

SIR,-The excellent article by Wing Commander H F Oxer (20 September, p 692) has drawn attention to the problems involved in aeromedical flights. Having assessed a patient as suitable for transportation by air the doctor or hospital is often faced with the problem of organising a suitable flight. The St John Ambulance aeromedical service operates a unique voluntary 24-hour international emergency travel service by air ambulance charter or by airline scheduled flights for the escort of patients to or from any part of the world and within the UK. Air ambulance flights are particularly useful for seriously ill patients who may require considerable in-flight care. There is the additional advantage of being able to land at a much greater number of airports, the patient thus having to travel shorter road distances between airport and hospital.

The St John aeromedical service charters the following aircraft: HS125 jets, Cessna Golden Eagles, Navajo Chieftains, Islanders, Aztecs, and Senecas. Each aircraft has advantages and disadvantages compared with the others but with the range of aircraft available a comprehensive service is provided. On every flight a volunteer team of two or three air attendants (selected from a register of doctors, nurses, and lay members, all of whom have undergone additional aeromedical training) take standard medical packs which include oxygenation, automatic ventilation, resuscitation, intubation, and intravenous equipment. At present the service covers the whole of Western Europe and North and West Africa.

When escorting cases on airline soheduled services the St John service makes the necessary booking arrangements for stretcher fittings or sitting patients and for dealing with customs and immigration, the Foreign Office, embassies, and consuls. All St John air attendants carry the necessary international health documents. Patients are escorted to or from any part of the world and the air attendant will, if necessary, accompany the patient from the hospital bed in Britain to the hospital bed in the destination country or vice versa. I should be pleased to supply further information on request.

D H CLARK

Aeromedical Section

London SW 1

\section{Rhesus sensitisation associated with IUD} in pregnancy

SIR,-The title and conclusion of the above article by Dr J S McCracken (20 September, p 684) suggest that the intrauterine device (IUD) was the agent responsible for causing sensitisation and production of antibody in the Rh-negative mother. However, there are other more likely explanations for the sensitisation. She could have been sensitised by the 1967 full-term pregnancy and not stimulated by the subsequent abortions, or she could have been sensitised by one of the abortions, even the second one, which could represent a failure of anti-D $\gamma$-globulin. Again, women have been known to become sensitised and produce antibody in a first pregnancy and thus her last pregnancy could have sensitised her and produced the antibody before term irrespective of the IUD. Allo-sensitisation and production of antibody in the same pregnancy are rare, however, and this would argue against the IUD as a likely cause.

In view of the other possibilities and the rarity of antibody appearing in the first sensitising pregnancy, we would consider the evidence against the IUD to be extremely weak.

Law Hospital,

MaLCOLM D BLACK Carluke Lanarkshire JEAN Y MACDOUGALL

\section{Patients or criminals?}

SIR,-If, as your leading article (11 October, p 70) states "a single institution cannot .... set out to be a therapeutic community and at the same time have the security of a prison," then what kind of community is a hospital such as Broadmoor supposed to be?

For obvious reasons much attention is rightly given to the needs of those patients who are likely to leave Broadmoor in the near future. No one would dispute the fact that such patients need psychotherapy, and to be well enough to leave is one of the goals. But what of the needs of those who are unlikely to leave?

It is a bleak outlook if a single institution, such as this hospital, cannot be both a therapeutic community and at the same time have the security of a prison. Patients who live in a hospital "without limit of time" live in a secure setting, though, in the interests of humanity, they also have a right to live in a therapeutic community. To this end the therapeutic energy of all professional disciplines converges.

If the concept of a "therapeutic community" is sacrificed on the altar of "security" (or vice versa), then an essential quality of the life within Broadmoor Hospital would be lost. Patients who may never leave and, vicariously, the wider community would be the losers.

Broadmoor Hospital,
Crowthorne, Berks

MURRAy COX

\section{Epidemiology of poliomyelitis in Scotland}

SIR,-We wish to correct from 11 to 10 the number of poliomyelitis cases in Scotland during 1970-4 reported in our letter (2 August, p 304), because of a late corrected diagnosis of meningioma in one of the serologically diagnosed cases. This illustrates the uncertainty of virological diagnosis when patients are investigated too late for successful virus isolation or detection of unequivocal rising antibody titres. The high titres of antibody in this patient may have been due to known close contact with children who had recently received oral polio vaccine.

Despite the difficulty of interpretation, the finding of unchanging but unusually high antibody titres should not be ignored since in some cases it provides the only virological evidence available, suggesting "recent infection," the significance of which must be interpreted in the light of the associated clinical and epidemiological data. The practical lesson remains-the need for clinical awareness of the possibility of poliomyelitis and for the prompt submission of appropriate stool and blood specimens to facilitate early virological confirmation.

We are grateful to Dr W J Patterson, Community Medicine Specialist, Ayrshire and Arran Health Board, for notifying us of the altered diagnosis and providing other information about this case.

N R GRIST ELEANOR J BELL

DANIEL REID

University Department of Infectious Diseases,

Regional Virus Laboratory, and

Communicable Diseases (Scotland) Unit,

Ruchill Hospital,
Glasgow

\section{Enteric-coated aspirin overdose and} gastric perforation

SIR,-The short report of enteric-coated aspirin overdose and gastric perforation (11 October, p 85) will no doubt be added to the apocrypha of aspirin toxicity, but certain aspects of the case and case report make it very unlikely that this was "a case of fatal gastric perforation due to Safapryn." The following doubts immediately spring to mind.

The patient was being treated for arthritis with Safapryn six tablets, phenylbutazone $300 \mathrm{mg}$, ampicillin $1 \mathrm{~g}$, and ethylestrenol $2 \mathrm{mg}$ daily and nitrazepam $5 \mathrm{mg}$ nightly. Why do the authors immediately attribute the gastric erosions and perforations to enteric-coated aspirin when phenylbutazone is a perfectly respectable gastric irritant, and since when have ampicillin and ethylestrenol been used for treatment of arthritis, even of arthritis unspecified ? More important, what role did a paracetamol overdose of $16.75 \mathrm{~g}$ play in this 83-year-old patient's sudden deterioration and death? As the residues of 67 Safapryn tablets were found in the stomach it implies that she ingested $67 \times 250 \mathrm{mg}$ of paracetamol. The blood paracetamol level is well within the toxic range, although to assess critically this level one would need to know the temporal relation between her overdose-presumably unknown - and death and also her renal and hepatic function. Death may occur with paracetamol overdoses of $5-20 \mathrm{~g}$, and liver damage may be expected after the ingestion of more than $15 \mathrm{~g} .{ }^{1}$ No comment is made on the histological appearances of liver and kidneys.

In conclusion, the gastric ulcers and perforations found may well have been terminal events following a fatal paracetamol overdose, and the enteric-coated aspirin residues little more than innocent bystanders.

J M GUMPEL

Northwick Park Hospital,

Harrow, Middlesex

1 Proudfoot, A T, and Wright, N, British Medical fournal, 1970, 3, 557 .

\section{Low-dose heparin and prevention of} venous thromboembolic disease

SIR,-Your leading article (23 August, p 447) on low-dose heparin and the prevention of venous thromboembolic disease covers the subject well but calls for some comment when it moves on to consider other prophy- 